\title{
Serum macrophage migration inhibition factor for diagnosing endometriosis and its severity: case-control study
}

Sahar Mohamed Yehya Elbaradie* (D), Mohamed Sobhy Bakry and Almandouh Hussein Bosilah

\begin{abstract}
Background: Endometriosis is a long-standing progressive disease that affects women of reproductive age. Macrophage migration inhibitory factor (MIF) is one of non-invasive blood biomarker that was detected in sera of endometriotic patients. The present study aimed to determine the accuracy of serum MIF in diagnosing endometriosis in women with infertility and chronic pelvic pain, and correlate its level to the stage of the disease.

Methods: Observational case-control study conducted at Fayoum University hospital from March 2016 till September 2018. Three hundred women candidate for diagnostic laparoscopy for either infertility or gynecologic chronic pelvic pain were included. The study group included patients with symptoms suggestive of endometriosis or chocolate cyst by ultrasound and proved by laparoscopy and histopathology. The control group included other causes of infertility or pelvic pain. All patients undergone either diagnostic or operative laparoscopy, and before laparoscopy blood sampling for quantitative measurement of macrophage migration inhibitory factor (MIF) protein in serum by ELISA technique.
\end{abstract}

Results: The level of serum MIF was significantly higher in endometriosis group compared to control group (1.75 \pm $1.48 \mathrm{pg} / \mathrm{ml}$ and $0.51 \pm 0.45 \mathrm{pg} / \mathrm{ml}$, respectively, $\mathrm{P}=<0.001$ ), with a progressive increase with advancing stage (stage I, $1.3 \pm 1.03 \mathrm{pg} / \mathrm{ml}$, stage II, $1.7 \pm 1.57 \mathrm{pg} / \mathrm{ml}$, stage III, $2.1 \pm 1.19 \mathrm{pg} / \mathrm{ml}$ and in stage IV, $3.2 \pm 2.6 \mathrm{pg} / \mathrm{ml})$. Moreover, in patients presented with pain and infertile patients showed significantly higher levels of serum MIF (1.92 \pm 1.13 vs $1.21 \pm 1.17$ and $1.82 \pm 1.13$ vs $1.32 \pm 0.91$ respectively with $p$-value $<0.001)$. ROC curve of serum MIF with a cut off value of $0.85 \mathrm{pg} / \mathrm{ml}$ or more achieves a sensitivity of $80.6 \%$, specificity of $83.3 \%$, positive predictive value of $82.9 \%$ and negative predictive value of $81.2 \%$.

Conclusion: Serum MIF might be a promising marker not only for noninvasive diagnosis of endometriosis but as a target for detecting severity as well.

Keywords: Serum macrophage migration inhibition factor, Endometriosis, Laparoscopy, Infertility, Chronic pelvic pain, Diagnosis

* Correspondence: sbaradie@gmail.com

Obstetric and Gynecology Department, Fayoum University, 23 Mohammed Gonemy of mohammed Elmakreef 6th district, nasr city, Cairo, Fayoum, Egypt

C C The Author(s). 2020 Open Access This article is licensed under a Creative Commons Attribution 4.0 International License, which permits use, sharing, adaptation, distribution and reproduction in any medium or format, as long as you give appropriate credit to the original author(s) and the source, provide a link to the Creative Commons licence, and indicate if changes were made. The images or other third party material in this article are included in the article's Creative Commons licence, unless indicated otherwise in a credit line to the material. If material is not included in the article's Creative Commons licence and your intended use is not permitted by statutory regulation or exceeds the permitted use, you will need to obtain permission directly from the copyright holder. To view a copy of this licence, visit http://creativecommons.org/licenses/by/4.0/. The Creative Commons Public Domain Dedication waiver (http://creativecommons.org/publicdomain/zero/1.0/) applies to the data made available in this article, unless otherwise stated in a credit line to the data. 


\section{Synopsis}

The level of serum macrophage migration inhibitory factor (MIF) is higher in endometriotic patients and is correlated with disease stage, fertility and pain.

\section{Background}

Endometriosis is an estrogen-dependent, complex and mysterious disease, rarely detected after menopause and before menarche [1]. Despite being a benign gynecologic disease, endometriosis is supposed to mainly result from abnormal invasion and survival of endometrial glands and stroma outside the uterine cavity $[2,3]$. Clinically it forms three types of gross lesions: superficial peritoneal lesions, endometriomas or ovarian endometriotic cysts and deep infiltrating lesions [4].

Risk factors, etiology, pathogenesis, and symptomatology vary considerably and still could not be explained. Moreover, there is a great debate about the nature of endometriosis as progressive chronic disease [5].

In 2017 Lagana et al. in their study based on understanding of genetic, epigenetic and biological mechanisms that regulate the development and differentiation of the urogenital tract during intrauterine life, proposed a theory that harmonized the pathogenesis of endometriosis. They hypothesized that, alternation and uncontrol within the mesoderm due to a deregulation of genes leads abnormal placing of stem cells with endometrial phenotype during organogenesis and keep them in an inactive slots. Alternation/activation of peritoneal microenvironment by pro-inflammatory cytokines, adhesion molecules, immune cells and extracellular matrix metalloproteinase create the conditions for survival of ectopic endometrial cells by differentiation, adhesion, and proliferation- +- . What triggers such alterations was not clear, that's why in their later review, they concluded that a single etiopathogenetic model is not sufficient to explain its complex pathobiology [6, 7].

Overall, most investigators agree that immune dysfunctions, genetic predisposition, hormonal factors and environmental toxins in addition to retrograde menstruation are all-important for initiating the aberrant growth of ectopic endometrium [3, 8]. Abnormal immune and inflammatory changes may be responsible for major symptoms of endometriosis and may have a role for endometrial tissue growth in ectopic areas and development of endometriosis [2]. Yang, et al. and more recently Rakhila et al. in their studies concluded that macrophage migration inhibitory factor (MIF), a potent mitogenic factor for human endothelial cells, could be secreted by endometriotic cells to directly or indirectly stimulate cell proliferation [2, 9].

The prevalence of endometriosis is known to be underestimated because laparoscopy, with or without histological verification, being both successful and safe, is considered the gold standard method to confirm the diagnosis [10]. Although, the literature on the diagnostic value, complications and adverse events of a laparoscopy is very limited, it is safely sure to exclude the diagnosis of endometriosis in women with symptoms and signs of the disease with a negative diagnostic laparoscopy [11]. This attributed to the worldwide known reporting of diagnostic delay between onset of symptoms and diagnosis of endometriosis [12].

In an attempt to introduce non-invasive diagnosis of endometriosis, May et al. in their systematic review identified over 200 possible immunological biomarkers, and concluded that none had been clearly shown to be of clinical use [13]. Furthermore, a Cochrane study reviewed one hundred forty-one studies that evaluated one hundred twenty-two blood biomarkers for endometriosis. These biomarkers included hormones, molecules of cell adhesion, microRNAs (miRNA), inflammatory/ apoptosis markers, immune system markers, oxidative stress markers, growth factors, angiogenesis factors, and other proteins [14]. Authors' concluded that there is a proven advantage of a subset of blood biomarkers for both detecting pelvic endometriosis and for differentiating benign ovarian masses from ovarian endometriomas, however, none of these biomarkers have precise accuracy to be used outside a research setting.

Macrophage migration inhibitory factor (MIF), is one of a non-invasive blood biomarkers that was expressed in endometriosis and has been suggested to have a pivotal role in the pathogenesis of endometriosis as well as infertility and pelvic pain [9]. This pro-inflammatory cytokine could, directly and indirectly, foster angiogenesis, activate proliferation of cells, provoke prostaglandin E synthesis (PGE), and stimulate local synthesis of estradiol in stromal cells of endometriotic tissue was supported by recent studies [15-17].

In 2002, Kats et al. documented increased levels of peritoneal fluid MIF in women with endometriosis that was significantly higher in infertile endometriotic women [18]. Later, in 2005, Cao et al. reported that serum MIF was more than 3 folds higher in women suffering from endometriosis than normal control and its highest level was detected in the advanced stage disease (III-IV); clarifying a reasonable link between MIF and the progression of the disease [19]. Further studies also showed markedly elevated levels of MIF in the peripheral blood [20], as well as in the ectopic endometrial tissue [21] of women with endometriosis elucidating a close relationship between MIF and the pathophysiology of endometriosis, especially in those who had pelvic pain and were infertile.

The present study aimed to evaluate the value of serum macrophage migration inhibitory factor in diagnosing endometriosis in women with infertility and 
chronic pelvic pain and correlate its level with the stage of the disease.

\section{Methods \\ Design}

A case-control observational study from March 2016 till September 2018.

\section{Setting}

The study was conducted at Fayoum University Hospital.

\section{Patients}

Women in the childbearing period presenting with either gynecologic chronic pelvic pain (CPP) or infertility indicated and fit for diagnostic laparoscopy were allocated to either groups of the study. The study group included 150 patients with symptoms suggestive of endometriosis or chocolate cyst by ultrasound and proved by laparoscopy and histopathology. The control group included 150 patients with other causes of infertility or pelvic pain. All women must have no hormonal treatment or surgical intervention for the last 3 months. The patients' cycle history was documented to determine the cycle phase (proliferative or secretory) and include those of the follicular phase of the cycle. Women suffering from autoimmune, degenerative or neoplastic diseases (e.g chronic/ulcerative colitis, diabetes mellitus, rheumatoid arthritis, multiple sclerosis, asthma, suspicion of malignancy), those with a bleeding tendency or active infection or where laparoscopy is contraindicated were excluded from the study.

Each patient was subjected to informed written consent, detailed medical history, thorough physical and gynecological examinations, laboratory routine preoperative investigations and postoperative histopathological evaluation of biopsy samples of endometriotic lesions. Besides, all patients had a preoperative evaluation by transvaginal ultrasonography (TVU) for assessment of uterine size, uterine cavity, endometrial thickness, exclude other pelvic pathology and search for endometriosis, site, size, and surroundings.

\section{MIF assay}

Five milliliters were collected from the antecubital fossa vein on the morning following admission and before laparoscopy. The collected blood samples were allowed to coagulate at room temperature and centrifuged for $10 \mathrm{~min}$ at $3500 \mathrm{rpm}$ to separate cellular elements. The serum was decanted, aliquoted, and stored at $-80^{\circ} \mathrm{C}$ for further assessment.

Quantitative measurement of MIF protein in serum was measured by ELISA technique following the manufacturer's protocols \{Sandwich assay procedure, sensitivity 6 $\mathrm{pg} / \mathrm{mL}$; standard curve range: $8.23-6000 \mathrm{pg} / \mathrm{mL}$; coefficient of variations (CVs) of intra-assay: $<10 \%$; CVs of inter-assay: $<12 \%\}$.

In brief, this technique uses captured mouse monoclonal anti-human-MIF antibody (R\&D Systems, Minneapolis, $\mathrm{MN}$ ), a rabbit polyclonal antihuman-MIF antibody for detection, alkaline phosphatase-conjugated goat antirabbit IgGs (Chemicon International Inc., Temecula, CA), and para-nitrophenyl phosphate as substrate (RAB0360, Sigma-Aldrich,Inc. Mereck, KGa, Darmstadt, Germany). The optical density was measured at $405 \mathrm{~nm}$, and MIF concentrations were extrapolated from a standard curve using recombinant human MIF. Samples in the MIF ELISA assay were run in duplicate.

\section{Laparoscopy and biopsy}

Laparoscopy was performed for all patients and biopsy from study group. Endometriosis was confirmed by visual inspection and subsequent histopathological evaluation of laparoscopic biopsies of suspected lesions in a hundred and fifty participants (study group).

The control group, having no visible evidence of endometriosis, included cases of polycystic ovaries, chronic pelvic inflammatory disease, simple ovarian cysts, pelvic adhesions, uterine anomalies, para-ovarian cyst, hydrosalpinx or were laparoscopically free. Endometriosis staging according to the revised American Fertility Society classification (ASRM) point system 1997 was used [22]. Stage I disease (1-5 points) included women with minimal and few superficial implants, stage II (6-15 points) those with mild and more deeper implants, stage III (16-40 points) those with moderate, many deep implants, small cysts on one or both ovaries or presence of filmy adhesions and stage IV disease ( $>40$ points) included more severe, deep implants, large cysts on one or both ovaries and many dense adhesions. Fig. 1 demonstrates flow chart of the methodology.

\section{Statistical analysis}

Data were statistically described in terms of mean \pm standard deviation ( $\pm \mathrm{SD}$ ), median and range, or frequencies (number of cases) and percentages when appropriate. Comparison of numerical variables between the study groups was done using the Student $t$-test for independent samples in comparing 2 groups and oneway analysis of variance (ANOVA) test with posthoc multiple 2-group comparisons when comparing more than 2 groups. For comparing categorical data, Chisquare $(\mathrm{X} 2)$ test was performed. Accuracy was represented using the terms sensitivity, specificity, positive predictive value, and negative predictive value. Receiver operator characteristic (ROC) analysis was used to determine the optimum cut off value for MIF in diagnosing endometriosis. Two-sided $p$ values less than 0.05 were 


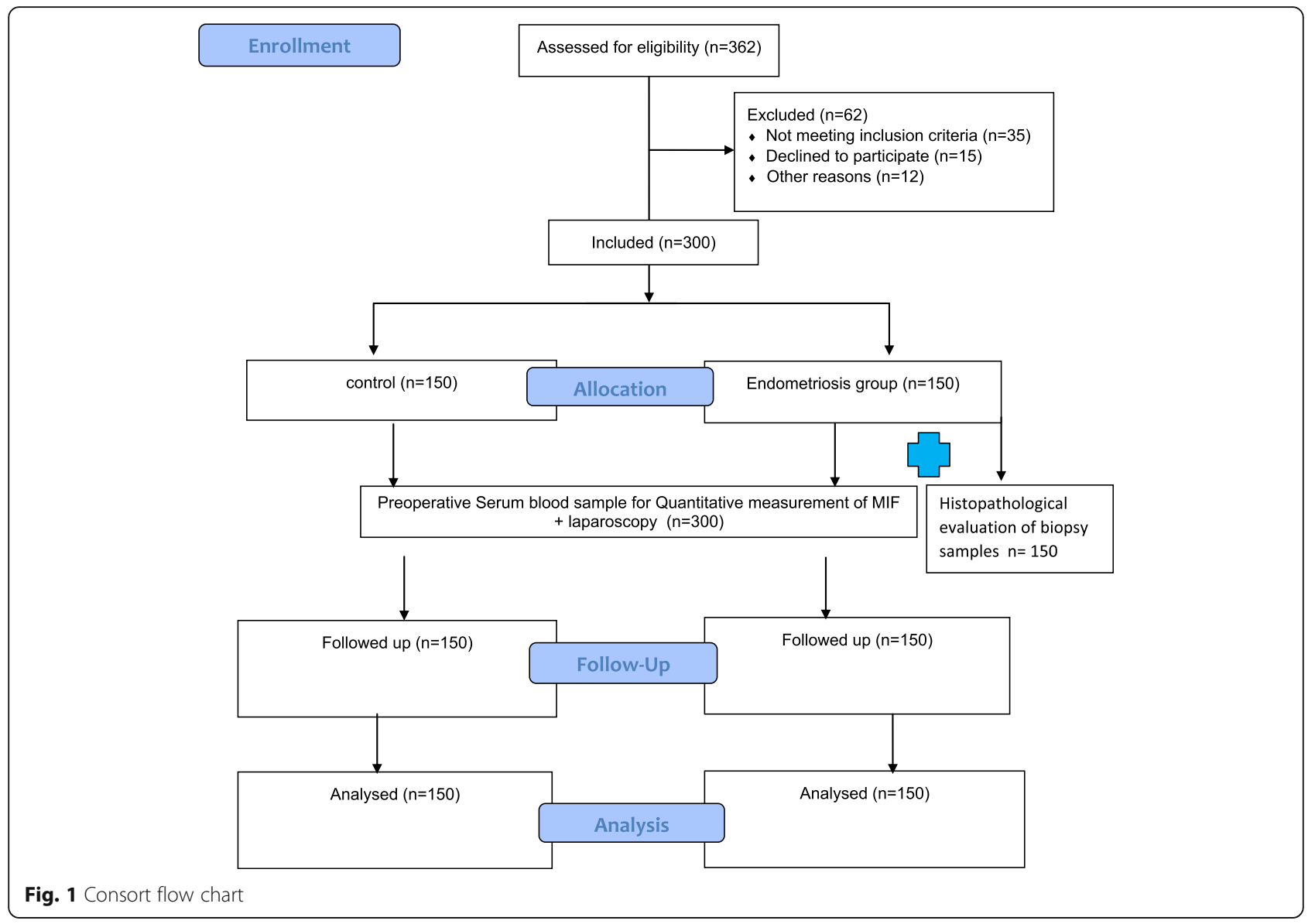

considered statistically significant. All statistical calculations were done using computer program IBM SPSS (Statistical Package for the Social Science; IBM Corp, Armonk, NY, USA) release 22 for Microsoft Windows.

\section{Sample size}

Calculation was done using the comparison of macrophage migration inhibitory factor (MIF) between the 4 stages of endometriosis. As reported in a previous publication [20], the mean \pm SD of MIF in stage I-II of endometriosis was approximately $1.36 \pm 0.27 \mathrm{ng} / \mathrm{ml}$, while in stages III-IV it was approximately $3.12 \pm 0.79 \mathrm{ng} / \mathrm{ml}$. Accordingly, we calculated that the minimum proper sample size was 15 cases in each stage. Since the prevalence of stage IV is approximately $10 \%$, we decided to include 150 cases of endometriosis and 150 control women to be able to reject the null hypothesis with $80 \%$ power at $\alpha=0.05$ level using Student's t-test for independent samples. Sample size calculation was done using PS Power and Sample Size Calculations software, version 3.0.11 for MS Windows (William D. Dupont and Walton D., Vanderbilt University, Nashville, Tennessee, USA).
ClinicalTrials.gov ID trial number

NCT04091997 date of registration 9/13/2019 "Retrospectively registered" URL:https://register.clinicaltrials. gov/prs/app/action/SelectProtocol?sid=S000980H\&selectaction $=$ Edit\&uid $=$ U0004QXE\&ts $=3 \& c x=1 j \mathrm{~d} 2 \mathrm{jm}$

\section{Results}

Both groups were comparable regarding age, parity, body mass index, symptoms and type of infertility (Table 1). The endometriosis group included 75 women of stage I, 21 women of stage II, 39 women of stage III and 15 women of stage IV. The control group included 33 women with polycystic ovary disease (PCO), 28 women with pelvic inflammatory disease (PID), 27 women with simple ovarian cyst, 32 women with pelvic adhesions 6 women with uterine anomalies, 2 women with paraovarian cysts, one with hydrosalpinx and 21 women were laparoscopically normal (Table 1 ).

Women with endometriosis showed more than double-fold increase in serum MIF than nonendometriotic matched women $(1.75 \pm 1.48 \mathrm{pg} / \mathrm{ml}$ vs $0.51 \pm 0.45 \mathrm{pg} / \mathrm{ml}$ respectively), with a statistically significant difference between groups $(p<0.001)$ (Table 2). 
Table 1 Baseline characteristics of endometriotic and non-endometriotic control women

\begin{tabular}{|c|c|c|c|}
\hline & Endometriosis $(\boldsymbol{n}=150)$ & Control $(n=150)$ & $\boldsymbol{p}$ value \\
\hline Age (years) & $28.1 \pm 4.2$ & $27.8 \pm 3.9$ & 0.552 \\
\hline \multicolumn{4}{|l|}{ Parity: } \\
\hline$-\mathrm{PO}$ & $72(48.0 \%)$ & 69 (46.0\%) & \multirow[t]{2}{*}{0.729} \\
\hline$-P 1-4$ & $78(52.0 \%)$ & $81(54.0 \%)$ & \\
\hline $\mathrm{BMI}\left(\mathrm{kg} / \mathrm{m}^{2}\right)$ & $26.9 \pm 2.7$ & $27.2 \pm 2.6$ & 0.328 \\
\hline \multicolumn{4}{|l|}{ Symptoms: } \\
\hline - Pain & $114(76.0 \%)$ & $105(70.0 \%)$ & 0.242 \\
\hline - Infertility & $129(86.0 \%)$ & $123(82.0 \%)$ & 0.345 \\
\hline \multicolumn{4}{|l|}{ Type of infertility: } \\
\hline - Primary & $72(55.8 \%)$ & $69(56.1 \%)$ & \multirow[t]{2}{*}{0.964} \\
\hline - Secondary & $57(44.2 \%)$ & $54(43.9 \%)$ & \\
\hline \multicolumn{4}{|l|}{ Endometriosis stage: } \\
\hline - Stage I & 75 (50.0\%) & & \multirow[t]{4}{*}{-} \\
\hline - Stage II & $21(14.0 \%)$ & & \\
\hline - Stage III & $39(26.0 \%)$ & & \\
\hline - Stage IV & $15(10.0 \%)$ & & \\
\hline \multicolumn{4}{|l|}{ Lesions in control: } \\
\hline$-\mathrm{PCO}$ & & $33(22.0 \%)$ & \multirow[t]{8}{*}{-} \\
\hline - PID & & $28(18.7 \%)$ & \\
\hline - Simple ovarian cyst & & $27(18.0 \%)$ & \\
\hline - Adhesions & & $32(21.3 \%)$ & \\
\hline - Uterine anomalies & & $6(4 \%)$ & \\
\hline - Paraovarian cyst & & $2(1.3 \%)$ & \\
\hline - hydrosalpinx & & $1(0.67 \%)$ & \\
\hline - No lesion & & $21(14.0 \%)$ & \\
\hline
\end{tabular}

BMI Body mass index, PCO Polycystic ovary, PID Pelvic inflammatory disease

Moreover, the level of serum MIF differed according to the stage of endometriosis with progressive increase with advancing stage (stage I $1.3 \pm 1.03 \mathrm{pg} / \mathrm{ml}-75$ patient, stage II $1.7 \pm 1.57 \mathrm{pg} / \mathrm{ml}-21$ patient, stage III $2.1 \pm 1.19$ $\mathrm{pg} / \mathrm{ml}-39$ patient, and in stage IV $3.2 \pm 2.6 \mathrm{pg} / \mathrm{ml}-15$ patient) (Table 3). Subgroup analysis of serum MIF in different stage disease also showed a statistically significant difference between stage I and stage II, stage II and stage III $(p>0.999)$, stage I and stage IV $(p<0.001)$, but no significant difference between stage II or stage III and stage IV (p 0.009 and 0.057 respectively).

As regard symptomatology in endometriotic patients, infertile patients had significantly higher levels of serum
MIF compared to fertile endometriotic patients $(1.87 \pm$ $1.54 \mathrm{pg} / \mathrm{ml}$ vs $1.05 \pm 0.74 \mathrm{pg} / \mathrm{ml}$ respectively, $\mathrm{p}<0.001)$, with significantly higher levels in those with primary infertility compared to those with secondary infertility $(2.3 \pm 1.72 \mathrm{pg} / \mathrm{ml}$ vs $1.32 \pm 1.07 \mathrm{pg} / \mathrm{ml}$ respectively, $p<$ $0.001)$. Moreover, there was a statistically significant difference in serum MIF in patients presented with pain in comparison to those without pain $(2.02 \pm 1.54 \mathrm{pg} / \mathrm{ml}$ and $0.871 \pm 0.83 \mathrm{pg} / \mathrm{ml}$ respectively, $p$-value $<0.001$ ) (Table 4).

Receiver operating characteristics (ROC) curve was used to define the best cut off value of MIF to diagnose endometriosis, which was $0.85 \mathrm{pg} / \mathrm{ml}$ or more. This

Table 2 Comparison of serum macrophage migration inhibitory factor (MIF, pg/ml) between endometriotic patients and those without endometriosis

\begin{tabular}{llll}
\hline MIF $(\mathrm{pg} / \mathrm{ml})$ & Endometriosis $(\mathrm{n}=150)$ & No-endometriosis $(\mathrm{n}=150)$ & $\boldsymbol{p}$-value \\
\hline Mean $\pm \mathrm{SD}$ & $1.75 \pm 1.48$ & $0.51 \pm 0.45$ \\
Median (range) & $1.6(0.0-11.1)$ & $0.5(0.0-3.9)$ \\
$95 \% \mathrm{Cl}$ & $1.515-1.994$ & $0.439-0.583$ & $<001$ \\
\hline
\end{tabular}


Table 3 Comparison of serum macrophage migration inhibitory factor (MIF, pg/ml) between different endometriosis stages

\begin{tabular}{|c|c|c|c|c|c|}
\hline \multirow[t]{2}{*}{ MIF (pg/ml) } & \multicolumn{4}{|c|}{ Endometriosis Stage } & \multirow[b]{2}{*}{$\boldsymbol{p}$-value } \\
\hline & Stage I $(\boldsymbol{n}=75)$ & Stage $\|(\boldsymbol{n}=21)$ & Stage III $(\boldsymbol{n}=39)$ & Stage IV $(n=15)$ & \\
\hline Mean \pm SD & $1.3 \pm 1.03$ & $1.7 \pm 1.57$ & $2.1 \pm 1.19$ & $3.2 \pm 2.6$ & $<0.001$ \\
\hline Median (range) & $1.2(0.0-5.4)$ & $1.4(0.0-6.7)$ & $2.0(1.0-7.8)$ & $2.2(1.2-11.1)$ & \\
\hline $95 \% \mathrm{Cl}$ & $1.063-1.537$ & $0.985-2.415$ & $1.714-2.487$ & $1.759-4.641$ & \\
\hline
\end{tabular}

cutoff achieves a sensitivity of $80.6 \%$, specificity of $83.3 \%$, positive predictive value of $82.9 \%$ and negative predictive value of $81.2 \%$. (Fig. 2).

\section{Discussion}

Previous studies reported conflicting results regarding MIF level and mRNA expression across the menstrual cycle. Akoum et al. found a significant decrease of MIF protein in the mid- secretory phase and a significant increase of MIF protein in late secretory and mid-late proliferative phases [21]. Moreover, while Lin et al. and Zhang et al. demonstrated decreased secretory phase serum levels of MIF and MIF expression and increased proliferative phase MIF levels and MIF expression [23, 24], Kats et al. and Arcuri et al found no significant differences [25, 26]. Considering the conflicting results of the previous studies, we included women of the same menstrual cycle phase (immediate postmenstrual proliferative) phase.

In the present study, both endometriotic and control groups were comparable as regard age, parity, and body mass index (BMI). Infertility and the presence of chronic pelvic pain were also comparable. Infertility was recorded in 86 and $82 \%$ of patients and control groups respectively while chronic pelvic pain affected 76 and $70 \%$ of endometriosis and the control group respectively.
Elevated serum MIF in endometriotic patients compared to control in our study was supported by the study of Morin et al. [20] Serum MIF in their study ranged between $1.3580 \pm$ $0.2690-3.1234 \pm 0.7880 \mathrm{pg} / \mathrm{ml}$ and in our study, it ranged from $1.3 \pm 1.03-3.2 \pm 2.6 \mathrm{pg} / \mathrm{ml}$. The diversity of assay techniques, the improvement in the kits used, and the possible higher ongoing inflammatory process could explain these results.

In accordance with previous studies ${ }^{(21,24)}$ the level of serum MIF in our study was much higher in advancedstage disease than the early-stage disease $(1.3 \pm 1.03 \mathrm{pg} / \mathrm{ml}$ in stage I, $1.7 \pm 1.57 \mathrm{pg} / \mathrm{ml}$ in stage II, $2.1 \pm 1.19 \mathrm{pg} / \mathrm{ml}$ in stage III and $3.2 \pm 2.6 \mathrm{pg} / \mathrm{ml}$ in stage IV) suggesting a relationship with disease progression in the ectopic endometrium. However, our results contradict those of Kate et al., who demonstrated higher levels with active, early-stages and highly vascularized lesions [25]. They reported decreased production of MIF at the mRNA level in more advanced endometriotic lesions supporting a hypothesis that MIF could be a marker of active disease. Also, it contradicts the study of Lin et al. [23] that showed stageindependent MIF expression in ectopic endometrium. Although the explanation for these variations in the level of MIF in respect to the stage of the disease remains unknown and necessitate further investigation, it could be justified by the different numbers and disease stage of patients we studied (75 patients with stage I, 21 with stage II,

Table 4 Comparison of serum macrophage migration inhibitory factor (MIF, pg/ml) according to different symptomatology among endometriotic participants

\begin{tabular}{|c|c|c|c|}
\hline MIF (pg/ml) & Fertile $(n=21)$ & Infertile $(n=129)$ & $p$-value \\
\hline Mean $\pm S D$ & $1.05 \pm 0.74$ & $1.87 \pm 1.54$ & $0.019(S)$ \\
\hline Median (range) & $1.20(0.0-2.1)$ & $1.60(0.0-11.1)$ & \\
\hline $95 \% \mathrm{Cl}$ & $0.716-1.389$ & $1.599-2.137$ & \\
\hline MIF (pg/ml) & Primary infertility $(n=72)$ & Secondary infertility $(n=57)$ & p-value \\
\hline Mean $\pm S D$ & $2.30 \pm 1.72$ & $1.32 \pm 1.07$ & $<0.001(\mathrm{~S})$ \\
\hline Median (range) & $2.20(0.0-11.1)$ & $1.30(0.0-7.0)$ & \\
\hline $95 \% \mathrm{Cl}$ & $1.9-2.709$ & $1.034-1.602$ & \\
\hline MIF (pg/ml) & No Pain $(n=36)$ & Pain $(n=114)$ & p-value \\
\hline Mean \pm SD & $0.871 \pm 0.83$ & $2.02 \pm 1.54$ & $<0.001(\mathrm{~S})$ \\
\hline Median (range) & $0.90(0.0-2.9)$ & $1.70(0.0-11.1)$ & \\
\hline $95 \% \mathrm{Cl}$ & $0.587-1.156$ & $1.739-2.307$ & \\
\hline
\end{tabular}

(S) significant 


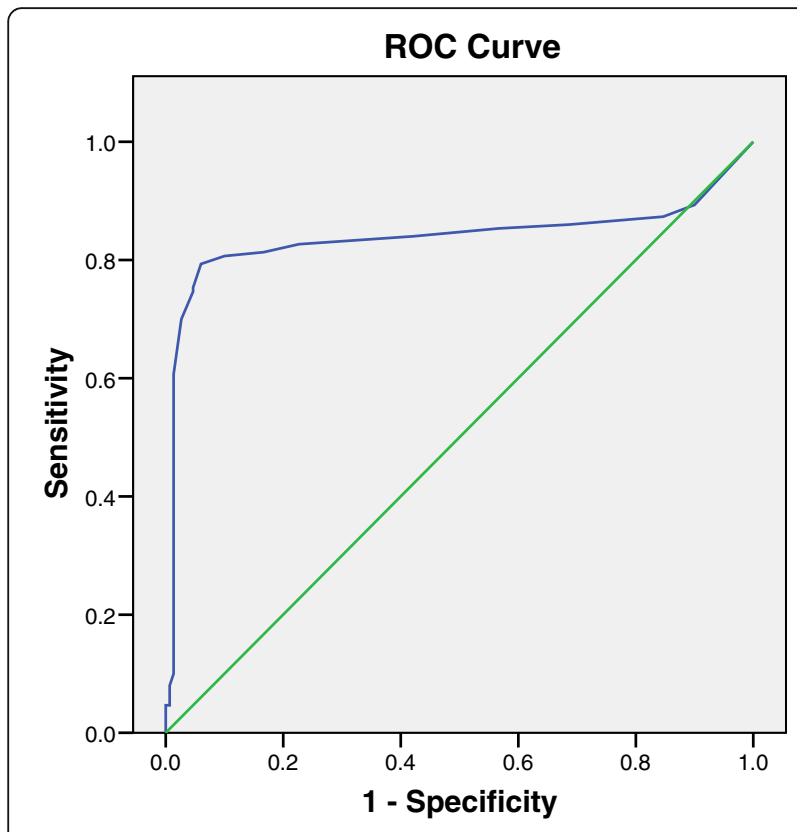

Diagonal segments are produced by ties.

Fig. 2 ROC curve

39 with stage III and 15 with stage IV) and those selected by Lin et al. (one patient with stage I, six with stage II, 22 with stage III and 11 with stage IV).

In our study, there was a significant difference in serum MIF between fertile endometriotic patients and those with either primary or secondary infertility. Moreover, there was a significant difference between those with primary infertility and those with secondary infertility suggesting a possible effect of MIF on endometrial receptivity. These results are supported by previous studies that detected a significant correlation between infertility and increased MIF levels in endometriotic women [20, 21, 23, 25]. Nevertheless, our results warrant further investigations to elucidate the possible role of MIF in endometriosisassociated infertility and how MIF could affect reproductive function particularly endometrial receptivity.

It is well known that endometriosis-associated pelvic pain is a symptom strongly related to disease existence, but not with disease load [27]. However, our findings supported by previous studies [21, 23, 25] of a significant difference between endometriotic patients with and without pelvic pain could elucidate the possibility that MIF may predict the severity of endometriosis. Though MIF involvement in abnormal bleeding associated with endometriosis, protease secretion induction, and the release of prostaglandins and other pain mediators, as reported in other studies [28, 29] was suggested as a possible role, the mechanisms of MIF's participation in pain associated with endometriosis, however, remain unclear.
A great strength of our study is the heterogeneity of the control group, including patients who had other pathologies for pain and infertility. This added further reliance on our study is specific to the serum marker tested for diagnosing endometriosis and not just nonspecific symptoms of the disease process of inflammation. Furthermore, the cutoff value of serum MIF in our study of $0.85 \mathrm{pg} / \mathrm{ml}$ achieved reliably high sensitivity, specificity, positive and negative predictive values, demonstrating the efficiency of the tested marker in diagnosing patients with endometriosis accurately. In clinical practice, this would probably make the diagnosis and follow up of endometriosis much easier without resorting to surgery and without the need for a panel of assays that was suggested by previous studies [30,31].

The present study is limited by the inclusion of only postmenstrual women and being a case-control study. Results would be more representative of the targeted population if a relationship between MIF and menstrual cycle phase was proven or refuted and by a cohort design to establish the accuracy of serum MIF to predict endometriosis among symptomatic women and detect the real prevalence of the disease.

\section{Conclusion}

Our study showed a significant increase of serum MIF in endometriotic patients that is correlated with disease stage, pain, and infertility and could be probably a promising marker not only for noninvasive diagnosis of endometriosis but as a target for detecting severity as well.

\section{Supplementary information}

Supplementary information accompanies this paper at https://doi.org/10. 1186/s12905-020-01051-0.

\section{Additional file 1.}

\section{Abbreviations}

MIF: Macrophage migration inhibitory factor; ELIZA: Enzyme-linked immunosorbent assay; mRNA: Messenger riboneucliec acid;

PGE: Prostaglandin E; CPP: Chronic pelvic pain; TVS: Transvaginal ultrasound; CVs: Coefficient of variations; ASRM: American Society of Reproductive medicine; ROC: Receiver operator characteristic; PCO: Polycystic ovary disease; PID: Pelvic inflammatory disease; BMI: Body mass index

\section{Acknowledgements}

We acknowledge the crucial help of Prof. Dr. Magdy Ibraheem, Prof of Obstetrics and Gynecology Cairo University, for his guidance, revision, and appraisal of manuscript statistics. The authors acknowledge the clinic staff, Fayoum University, and patients for their invaluable contributions to this research.

\section{Authors' contributions}

SMYE and AHB contributed to the design, conception and planning of the study. MSB and AHB performed the laparoscopy and collection of biopsy samples. SMYE analyzed and interpreted the data. MSB and AHB participated in the interpretation of the data. AHB wrote the first draft of the manuscript and SMYE substantively revised it. The authors read and approved the final version of the manuscript. 


\section{Funding}

The author reports no funding for their work.

\section{Availability of data and materials}

The datasets used and/or analyzed during the current study are available from the corresponding author on reasonable request.

\section{Ethics approval and consent to participate}

The study was performed in accordance with the Declaration of Helsinki ethical standards. The study was approved by Fayoum University ethical committee number R99. Informed written consent was taken from the study participants.

\section{Consent for publication}

Not applicable.

\section{Competing interests}

Authors decline any relevant financial, personal, political, intellectual, or religious interests.

Received: 21 February 2020 Accepted: 16 August 2020

Published online: 03 September 2020

\section{References}

1. Deroo BJ, Korach KS. Estrogen receptors and human disease. J Clin Invest. 2006;116(3):561-70. https://doi.org/10.1172/JCI27987 PMID: 16511588.

2. Rakhila H, Girard K, Leboeuf M, Lemyre M, Akoum A. Macrophage migration inhibitory factor is involved in ectopic endometrial tissue growth and peritoneal-endometrial tissue interaction in vivo: a plausible link to endometriosis development. PLoS One. 2014;9(10):e110434. https://doi.org/ 10.1371/journal.pone.0110434 eCollection 2014. PMID:25329068.

3. Giudice LC. Clinical practice. Endometriosis. N Engl J Med. 2010;362(25): 2389-98. https://doi.org/10.1056/NEJMcp1000274 PMID:2057392.

4. Scioscia M, Bruni F, Ceccaroni M, Steinkasserer M, Stepniewska A, Minelli L. Distribution of endometriotic lesions in endometriosis stage IV supports the menstrual reflux theory and requires specific preoperative assessment and therapy. Acta Obstet Gynecol Scand. 2011;90(2):136-9. https://doi.org/10. 1111/j.1600-0412.2010.01008.x Epub 2010 Dec 2. PMID : 21241258.

5. Canis M, Bourdel N, Houlle C, Gremeau A, Botchorishvili R, Matsu-zaki S. Endometriosis may not be a chronic disease: an alternative theory offering more optimistic prospects for our patients. Fertil Steril. 2016;105(1):32-4. https://doi.org/10.1016/j.fertnstert.2015.09.009 Epub 2015 Oct 9. PMID: 26453981

6. Laganà AS, Vitale SG, Salmeri FM, Triolo $O$, Frangež HB, Vrtačnik-Bokal E, et al. Unus pro omnibus, omnes pro uno: a novel, evidence-based, unifying theory for the pathogenesis of endometriosis. Med Hypotheses. 2017;103: 10-20. https://doi.org/10.1016/j.mehy.2017.03.032 Epub 2017 Mar 31

7. Laganà AS, Garzon S, Götte M, Viganò P, Franchi M, Ghezzi F, et al. The pathogenesis of endometriosis: molecular and cell biology insights. Int J Mol Sci. 2019;20(22):5615. https://doi.org/10.3390/ijms20225615 PMID: 31717614.

8. Bondza PK, Maheux R, Akoum A. Insights into endometriosis-associated endometrial dysfunctions: a review. Front Biosci (Elite Ed). 2009;1:415-28 PMID:19482656.

9. Yang Y, Degranpre P, Kharfi A, Akoum A. Identification of macrophage migration inhibitory factor as a potent endothelial cell growth promoting agent released by ectopic human endometrial cells. J Clin Endocrinol Metab. 2000;85(12):4721-7. https://doi.org/10.1210/jcem.85.12.7003 PMID: 11134134.

10. Johnson NP, Hummelshoj L, Adamson GD, Keckstein J, Taylor HS, Abrao MS, et al. World endometriosis society consensus on the classification of endometriosis. Hum Reprod. 2017;32(2):315-24. https://doi.org/10.1093/ humrep/dew293 Epub 2016 Dec 5. PMID: 27920089.

11. Wykes CB, Clark TJ, Khan KS. Accuracy of laparoscopy in the diagnosis of endometriosis: a systematic quantitative review. BJOG. 2004;111(11):120412. https://doi.org/10.1111/j.1471-0528.2004.00433.x.

12. Dunselman GA, Vermeulen N, Becker C, Calhaz-Jorge C, D'Hooghe T, De Bie $B$, et al. ESHRE guide-line: management of women with endometriosis. Hum Reprod. 2014;29(3):400-12. https://doi.org/10.1093/humrep/det457 Epub 2014 Jan 15. PMID: 24435778.
13. May KE, Conduit-Hulbert SA, Villar J, Kirtley S, Kennedy SH, Becker CM. Peripheral biomarkers of endometriosis: a systematic review. Hum Reprod Update. 2010;16:651-74.

14. Nisenblat V, PM PMB, Shaikh R, Farquhar C, Jordan V, Scheffers CS, et al. Blood biomarkers for the non- invasive diagnosis of endometriosis. Cochrane Database Syst Rev. 2016;(5):CD012179. https://doi.org/10.1002/ 14651858.CD012179 PMID: 27132058.

15. Veillat V, Carli C, Metz CN, Al-Abed Y, Naccache PH, Akoum A. Macrophage migration inhibitory factor elicits an angiogenic phenotype in human ectopic endometrial cells and triggers the production of major angiogenic factors via CD44, CD74, and MAPK signaling pathways. J Clin Endocrinol Metab. 2010;95(12):E403-12. https://doi.org/10.1210/jc.2010-0417 Epub 2010 Sep 8. PMID: 20829186.

16. Carli C, Metz CN, Al-Abed Y, Naccache PH, Akoum A. Up-regulation of cyclooxygenase-2 expression and prostaglandin E2 production in human endometriotic cells by macrophage migration inhibitory factor: involvement of novel kinase signaling pathways. Endocrinology. 2009;150(7):3128-37. https://doi.org/10.1210/en.2008-1088 Epub 2009 Mar 19. PMID: 19299454.

17. Bondza PK, Metz CN, Akoum A. Macrophage migration inhibitory factor upregulates alpha(v)beta(3) integrin and vascular endothelial growth factor expression in endometrial adenocarcinoma cell line Ishikawa. J Reprod Immunol. 2008;77(2):142-51. https://doi.org/10.1016/j.jri.2007.07.004 Epub 2007 Sep 12. PMID: 17854909.

18. Kats R, Collette T, Metz CN, Akoum A. Marked elevation of macrophage migration inhibitory factor in the peritoneal fluid of women with endometriosis. Fertil Steril. 2002;78(1):69-76. https://doi.org/10.1016/s00150282(02)03189-8 PMID: 12095493

19. Cao WG, Morin M, Metz C, Maheux R, Akoum A. Stimulation of macrophage migration inhibitory factor expression in endometrial stromal cells by interleukin, beta involving the nuclear transcription factor NFkappaB. Biol Reprod. 2005;73(3):565-70. https://doi.org/10.1095/biolreprod.104.038331 Epub 2005 May 18. PMID: 15901641.

20. Morin M, Bellehumeur C, Therriault MJ, Metz C, Maheux R, Akoum A. Elevated levels of macrophage migration inhibitory factor in the peripheral blood of women with endometriosis. Fertil Steril. 2005;83(4):865-72. https:// doi.org/10.1016/j.fertnstert.2004.10.039 PMID: 15820792

21. Akoum A, Metz CN, Al-Akoum M, Kats R. Macrophage migration inhibitory factor expression in the intrauterine endometrium of women with endometriosis varies with disease stage, infertility status, and pelvic pain. Fertil Steril. 2006;85(5):1379-85Epub 2006 Apr 17. https://doi.org/10.1016/j. fertnstert.2005.10.073.

22. Revised American Society for Reproductive Medicine classification of endometriosis: 1996. Fertil Steril. 1997;67(5):817-21. https://doi.org/10.1016/ s0015-0282(97)8139-x PMID: 9130884

23. Lin W, Chen S, Li M, Wang B, Qu X, Zhang Y. Expression of macrophage migration inhibitory factor in human endometriosis : relation to disease stage, menstrual cycle and infertility. J Obstet Gynaecol Res. 2010;36(2):34451. https://doi.org/10.1111/j.1447-0756.2009.01123.x PMID: 20492386.

24. Zhang $\mathrm{X}, \mathrm{Mu} \mathrm{L}$. Association between macrophage migration inhibitory factor in the endometrium and estrogen in endometriosis. Exp Ther Med. 2015;10(2):787-91. https://doi.org/10.3892/etm2015.2516 Epub 2015 May 22. PMID: 26622394

25. Kats R, Metz CN, Akoum A. Macrophage migration inhibitory factor is markedly expressed in active and early-stage endometriotic lesions. J Clin Endocrinol Metab. 2002;87(2):883-9. https://doi.org/10.1210/jcem.87.2.8260 PMID: 11836337

26. Arcuri F, Ricci C, letta F, Cintorino M, Tripodi SA, Cetin I, et al. Macrophage migration inhibitory factor in the human endometrium: expression and localization during the menstrual cycle and early pregnancy. Biol Reprod. 2001;64(4):1200-5. https://doi.org/10.1095/biolreprod64.4.1200 PMID: 11259268

27. Nothnick W, Alali Z. Recent advances in the understanding of endometriosis: the role of inflammatory mediators in disease pathogenesis and treatment. F1000Res. 2016:5. https://doi.org/10.12688/f1000research. 7504.1 PMID: 26949527.

28. Sales KJ, Jabbour HN. Cyclooxygenase enzymes and prostaglandins in pathology of the endometrium. Reproduction. 2003;126(5):559-67. https:// doi.org/10.1530/rep.0.1260559 PMID: 14611628.

29. Mitchell RA, Liao H, Chesney J, Fingerle-Rowson G, Baugh J, David J, et al. Macrophage migration inhibitory factor (MIF) sustains macrophage proinflammatory function by inhibiting p53: regulatory role in the innate 
immune response. Proc Natl Acad Sci U S A. 2002;99(1):345-50. https://doi. org/10.1073/pnas.012511599 Epub 2001 Dec 26. Doi: PMID: 11756671.

30. Seeber B, Sammel MD, Fan X, Gerton GL, Shaunik A, Chittams J, et al. Panel of markers can accurately predict endometriosis in a subset of patients. Fertil Steril. 2008;89(5):1073-81. https://doi.org/10.1016/j.fertnstert.2007.05. 014 Epub 2007 Aug 13. PMID: 17706208.

31. Ozhan E, Kokcu A, Yanik K, Gunaydin M. Investigation of diagnostic potentials of nine different biomarkers in endometriosis. Eur J Obstet Gynecol Reprod Biol. 2014;178:128-33. https://doi.org/10.1016/j.ejogrb.2014. 04.037 Epub 2014 May 6. Doi: 10.1016/j.ejogrb.2014.04.037. PMID: 24813083.

\section{Publisher's Note}

Springer Nature remains neutral with regard to jurisdictional claims in published maps and institutional affiliations.

Ready to submit your research? Choose BMC and benefit from:

- fast, convenient online submission

- thorough peer review by experienced researchers in your field

- rapid publication on acceptance

- support for research data, including large and complex data types

- gold Open Access which fosters wider collaboration and increased citations

- maximum visibility for your research: over $100 \mathrm{M}$ website views per year

At $\mathrm{BMC}$, research is always in progress.

Learn more biomedcentral.com/submissions 